\title{
Suitability of revision to MUSLE for estimating sediment yield in the Loess Plateau of China
}

\author{
Ya Luo ${ }^{1,2,3,4}$ - Shengtian Yang ${ }^{1,2,3} \cdot$ Xiaoyan Liu $^{5}$ Changming Liu ${ }^{6,7}$. \\ Yichi Zhang $^{1,2,3} \cdot$ Qiuwen Zhou ${ }^{1,2,3,4} \cdot$ Xu Zhou ${ }^{1,2,3,4} \cdot$ Guotao Dong $^{8}$
}

Published online: 30 August 2015

(C) Springer-Verlag Berlin Heidelberg 2015

\begin{abstract}
This study evaluated the effect of a combination of revisions to the cover and management factor $(C)$, support practice factor $(P)$, and topographic factor $(L S)$, and to determine the best use of each combination for modified universal soil loss equation (MUSLE) being applied in the Loess Plateau of China. Eight combinations were built based on common local methods of revision to factors $C, P$, and $L S$ in three ways (single factor revised, two factors revised, and three factors revised, respectively). By validating the effect of these combinations on sediment yield estimation using the Nash-Sutcliffe coefficient of efficiency (NSE), normalized root-mean-square error (NRMSE), correlation coefficient (R), and angle between liner trend line and 1:1 line, the optimal combination was selected. Results show that: (1) the original method significantly overestimates the sediment yield; (2) when
\end{abstract}

Shengtian Yang

yangshengtian@bnu.edu.cn

1 State Key Laboratory of Remote Sensing Science, Beijing, China

2 School of Geography, Beijing Normal University, Beijing, China

3 Beijing Key Laboratory for Remote Sensing of Environment and Digital Cities, Beijing, China

4 School of Geographic and Environmental Sciences, Guizhou Normal University, Guiyang, China

5 Yellow River Conservancy Commission, Zhengzhou, China

6 Institute of Geographic Sciences and Natural Resources Research, Chinese Academy of Sciences, Beijing, China

7 College of Water Science, Beijing Normal University, Beijing, China

8 Yellow River Institute of Hydraulic Research, Yellow River Conservancy Commission, Zhengzhou, China revising a single factor, the $L S$ factor revision has the greatest positive effect; (3) when revising two factors, the combination of a simultaneous revision to $C$ and to $P$ has the smallest angle between the liner trend line and the 1:1 line $\left(1.37^{\circ}\right)$; if the estimating accuracy of sediment peak is required, this combination may thus be a useful approach; and (4) when revising $C, P$, and $L S$ simultaneously, the combination has the highest NSE (0.76), lowest NRMSE (1.19), and the highest correlation coefficient (0.760), and may be used to estimate sediment yield. The suitability of MUSLE is enhanced using the common local revision to factors $C, P$, and $L S$. Under the assumption that level terrace spatial information can obtain effectively (or that there are few level terraces), these findings can be applied to the Loess Plateau for the design of soil and water conservation measures and for flood disaster assessment, and applied to future model applications in the Loess Plateau.

Keywords Suitability of MUSLE - Combination - Cover and management factor - Support practice factor .

Topographic factor . The Loess Plateau of China

\section{Introduction}

The modified universal soil loss equation (MUSLE) is a runoff-sediment model of optimizing hydrological model parameters, based on runoff characteristics, and is often used to estimate the sediment yield from rainstorm events for the outlet of the watershed (ASCE 1970; Williams and Berndt 1977). By replacing the rainfall factor with a runoff factor, sediment yield prediction accuracy is increased (Williams and Berndt 1977).To date, the MUSLE has been adopted to predict sediment yield in several regions, including America 
(Zhang et al. 2009; White et al. 2010), Iran (Sadeghi and Mizuyama 2007), Iraq (Mohammad et al. 2012), India (Jain et al. 2010), and China (Ouyang et al. 2010). Most of these studies have commonly revised MUSLE factors to improve its suitability for particular regions.

Estimation of rainstorm-generated sediment yield by means of a runoff-sediment model is an important way to quantitatively evaluate the effect of soil and water conservation measures and predict the risk of flooding in the Loess Plateau of China. The Loess Plateau region, located in Northern China, experiences arid and semi-arid climate conditions over an area greater than $600,000 \mathrm{~km}^{2}$ (Lü et al. 2012), and shows one of the highest erosion rates worldwide (Lal 2003).Recently, significant changes in runoff and sediment discharge in the area have been reported by many studies (Liang et al. 2013). The area's runoff and sediment yield are often dominated by rainstorms during the annual flood season of June-September (Mou 1996). The consequences of soil erosion have grown to the point that conservation of agricultural soils has become a matter of food security (Gates et al. 2011). At the same time, the rate of sediment deposits in the lower reaches of the Yellow River is causing the river bed to rise and is accompanied by floods (Shi and Shao 2000), adding to the difficulty of Yellow River basin flood disaster prevention. Thus, the estimation of rainstorm-generated sediment yield based on a runoff-sediment model with a shorter time interval will be a critical tool for the design of soil and water conservation measures and for flood disaster assessment in the Loess Plateau.

MUSLE may be useful to estimate the sediment yield in the Loess Plateau. However, due to various water conservation measures, the steep and fragmented topography, and its degenerated vegetation, the dominant erosion pattern and factors in the Loess Plateau area are different from those found in other parts of the world (Qiu et al. 2012). This should make the applicability of MUSLE for sediment yield estimation limited in this region because the factors of MUSLE have remarkable regional characteristics. For these reasons, revising the factors of MUSLE for improving its suitability in the Loess Plateau is an important contribution.

There has been much focus on revising the factors of MUSLE. For instance, Cai et al. (2000) paid more attention to the effect of vegetation coverage $(V C)$ on soil erosion, revising the cover and management factor $(C)$. Wang and Jiao (1996) revised the support practice factor $(P)$ based on the relationship between land utilization and water conservation measures. Liu et al. (1994), Liu et al. 2000) focused on the characteristics of the Loess Plateau's steep slope, and revised the slope gradient factor $(S)$ and slope length factor $(L)$. These studies undoubtedly represent positive developments for the suitability of MUSLE. However, many of them were primarily concerned with the effect of revising a single factor on the improvement of evaluation accuracy. An additional study is required to evaluate the comprehensive effect of multi-factor revision.

The objectives of this study are as follows: first, to select common local methods of revision to the cover and management $(C)$, support practice $(P)$ and topographic $(L S)$ factors of MUSLE; second, to evaluate the simulation accuracies of different combinations of revisions (i.e., original method, revised single factor, revised two factors, and revised three factors); finally, to put forward how each combination enhances MUSLE to estimate sediment yield in the Loess Plateau.

\section{Materials and methods}

\subsection{Study area}

The study area, Gushanchuan basin, is one of the most important regions in the Loess Plateau, and the Gaoshiya stream gauging station is near its outlet (Fig. 1). The basin is situated between $110^{\circ} 31^{\prime} 2^{\prime \prime} \mathrm{E}$ to $111^{\circ} 04^{\prime} 57^{\prime \prime} \mathrm{E}$ longitude and $39^{\circ} 0^{\prime} 3^{\prime \prime} \mathrm{N}$ to $39^{\circ} 27^{\prime} 29^{\prime \prime} \mathrm{N}$ latitude, covers more than $1272 \mathrm{~km}^{2}$ with an elevation ranging from 795 to $1414 \mathrm{~m}$ above mean sea level. The basin is characterized by dramatic topographical variation between the loess hills and the gully landforms, the gully density is $2.32 \mathrm{~km} / \mathrm{km}^{2}$. More than $90 \%$ of it is covered by loess. The average annual precipitation is $410 \mathrm{~mm}$. Nearly $80 \%$ of the precipitation is dominated by rainstorms occurring during the rainy season, from June to September. In addition,

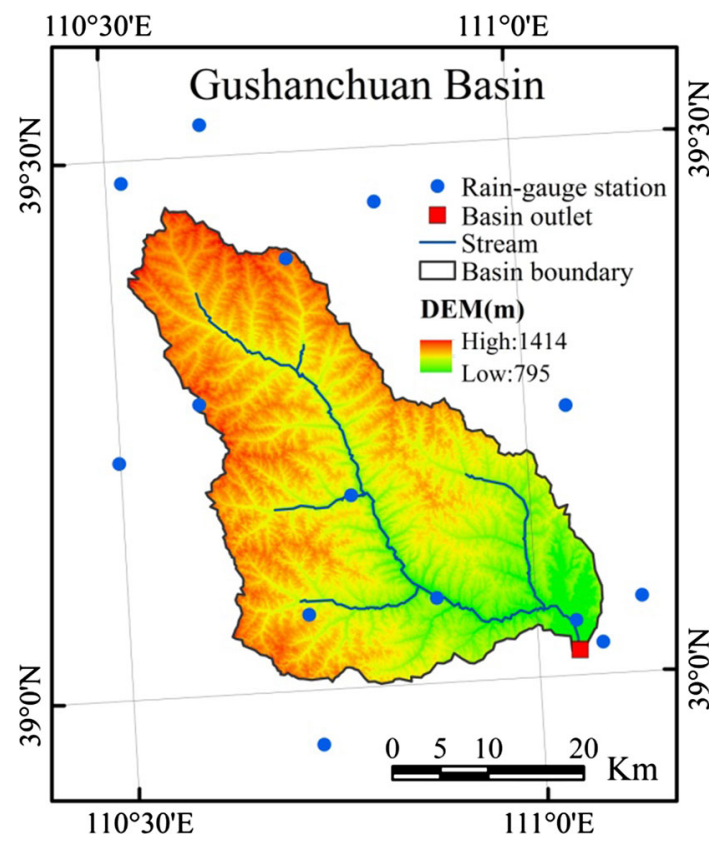

Fig. 1 Location of the study area 
approximately $75 \%$ of the annual discharge and $99 \%$ of the sediment yield is generated during the rainy season respectively (Wang et al. 2003).

\subsection{Sediment yield modeling based on MUSLE}

MUSLE is used to estimate sediment yield. This model estimates sediment yield for a given grid as a product of eight factors, whose values at a particular location can be expressed numerically and are given below (Williams 1995):

$S e d=11.8 \cdot\left(R s \cdot q_{\text {peak }} \cdot A_{\text {pixel }}\right)^{0.56} \cdot K \cdot C \cdot P \cdot L S \cdot C F R G$

where Sed is sediment yield (t), Rs is the surface runoff volume ( $\left.\mathrm{mm} \mathrm{ha}^{-1}\right), q_{\text {peak }}$ is the peak runoff rate $\left(\mathrm{m}^{3} \mathrm{~s}^{-1}\right)$, $A_{\text {pixel }}$ is the area of the grids (ha), $K$ is the soil erodibility factor, $C$ is the cover and management factor, $P$ is the support practice factor, $L S$ is the topographic factor, and $C F R G$ is the coarse fragment factor. Due to sediment yield is seen as a multiplier, so if one factor tends toward zero, the sediment yield will tend toward zero (Neitsch et al. 2009).

The study was carried out in four steps. For the first step we prepared the data for MUSLE, including rainfall data, soil data, remote sensing images, and digital elevation model (DEM). We then selected the estimation methods for all MUSLE factors. For the third step we compared the general accuracy of different combinations of sediment yield estimation with the effect of different combinations on sediment peak estimation. Finally, suitable revisions to MUSLE were suggested after validation. Figure 2 illustrates the proposed method with a flow chart.

\subsubsection{Multipliers $R s$ and $q_{\text {peak }}$, the surface runoff volume and the peak runoff rate}

The multiplier of $R s$ and $q_{\text {peak }}$, represents energy used in detaching and transporting sediment. Surface runoff can be simulated based on the distributed event flood forecasting model (Liu et al. 1965). For a given grid, by calculating the difference between precipitation and infiltration, the surface runoff can be obtained as the following equation describes:

$R s=P_{\text {rec }}-f$

where $R s$ is surface runoff $(\mathrm{mm}), P_{r e c}$ is precipitation( $\left.\mathrm{mm}\right)$, $f$ is infiltration(mm). Using a conceptual model, the infiltration is expressed mathematically:

$f=F \cdot P_{\text {rec }}^{r}$

where $f$ is infiltration ( $\mathrm{mm}$ ); parameter $F$ and $r$ values can be chosen by land types, and determined by the soil characteristics, vegetation, cover and antecedent soil moisture, etc. It is important to clarify that the distributed event flood forecasting model was developed through more than 300 artificial rainfall experiments in the Loess Plateau, and has often been applied to the Yellow River Basin in China for flood forecasting, water resources planning, and the like (Liu et al. 2008). The results of these practices indicate that the model is useful to simulate surface runoff in the Loess Plateau. Therefore, the distributed event flood forecasting model was selected to simulate the surface runoff for MUSLE.

The value of the peak runoff rate depends on the Rs. Its simulation accuracy is largely based on the simulation accuracy of the Rs. The value of the peak runoff rate is obtained from the following formula, recommended by Neitsch et al. (2009):

$q_{\text {peak }}=\frac{\alpha_{t c} \cdot R s \cdot A_{\text {pixel }}}{3.6 \cdot t_{\text {conc }}}$

where $q_{\text {peak }}$ is the peak runoff rate $\left(\mathrm{m}^{3} \mathrm{~s}^{-1}\right) ; \alpha_{t c}$ is the fraction of rainfall that occurs during the time of concentration (for short duration storms, all or most of the rain will fall during the time of concentration, so the value of $\alpha_{t c}$ is 1$)$; 3.6 is a unit conversion factor; $A_{\text {pixel }}$ is the area of the grids (ha); $t_{\text {conc }}$ is the time of concentration for the grid.

\subsection{2 $K$ and CFRG, the soil erodibility factor and the coarse fragment factor}

The multiplier of $K$ and $C F R G$, reflects the effect of soil properties on erosion. Different methods and erodibility indexes have been proposed in previous studies for soils in the Loess Plateau. Jiang and Zhu (1962) related the dispersion ratio and the coefficient of expansion of soil to its resistance to scouring and detachment by flow. Jiang (1978) and Li et al. (1990) measured the relative anti-scouribility indexes for loessial soils with experiments conducted in small flumes. Zhou and Wu (1993) introduced an erodibility index as the ratio of soil loss per unit runoff depth. However, the research cited so far was focused on measurable soil properties without directly relating soil erodibility indexes to measured soil loss under field conditions, moreover, due to the design criteria of plots used observe soil erodibility indexes were different, the research was very difficult to compare with each other (Zhang et al. 2001a, b; Zhang et al. 2004).

Depending on the properties of the soil itself, the values of $K$ can be calculated using Eq. (5) suggested by Williams (1995): 


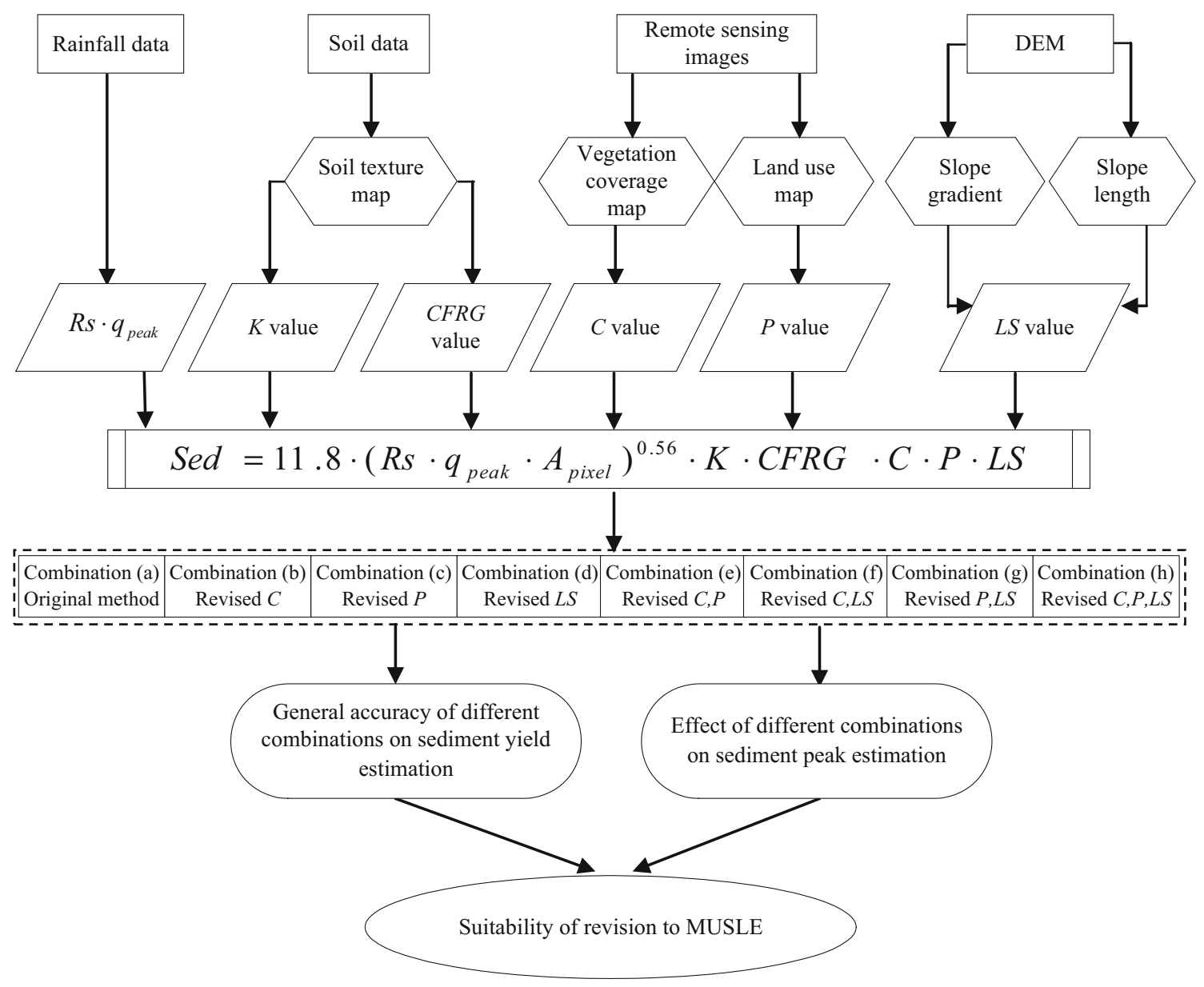

Fig. 2 The whole framework for the study

$$
\begin{aligned}
& K=\left\{0.2+0.3 \exp \left[-0.0256 S_{d}\left(1-\frac{S_{i}}{100}\right)\right]\right\}\left(\frac{S_{i}}{C_{i}+S_{i}}\right)^{0.3} \\
& {\left[1-\frac{0.25 C_{o r}}{C_{o r}+\exp \left(3.72-2.95 C_{o r}\right)}\right]} \\
& {\left[1-\frac{0.7\left(1-S_{d}\right)}{1-S_{d}+\exp \left(-5.51+22.9\left(1-S_{d}\right)\right.}\right]}
\end{aligned}
$$

where $K$ is the soil erodibility factor, $S_{d}$ is the percent of sand content (0.05-2.00 mm diameter particles), $S_{i}$ is the percent silt content $(0.002-0.05 \mathrm{~mm}$ diameter particles $), C_{i}$ is the percent clay content $(0.002 \mathrm{~mm}$ diameter particles $)$, $C_{o r}$ is the percent organic carbon content of the layer(\%). Equation (5) had been applied to evaluate the hydrological and erosional response of land use change in the Loess Plateau (Gao et al. 2012; Sun et al. 2014).

The $C F R G$ factor can be estimated using Eq. (6):

$$
C F R G=\exp (-0.053 \cdot \text { rock })
$$

where rock is the percent rock in the first soil layer (\%).

The estimation values of factors $K$ and $C F R G$ via Eq. (5) and (6) have been compared with other studies in the Loess Plateau of China (Zhang et al. 2001a, b; Shi 2009). The comparison shows that the estimation values are similar to the values studied by Zhang et al. (2001a), (b) and Shi (2009) (Table 1). Thus, the estimating methods of the $K$ and $C F R G$ factors were not revised for this study.

Among the factors of MUSLE, the estimation methods of the other factors, in addition to $R s, q_{p e a k}, K$, and $C F R G$, including the cover and management $(C)$, support practice $(P)$, and topographic $(L S)$ factors can be replaced by the common local methods. This replacement is showed in Sect. 2.3.

\subsection{Revision of factors $C, P$, and $L S$}

\subsubsection{C, the cover and management factor}

Vegetation affects the erosion capacity of surface runoff by changing the hydrodynamic characteristics of surface runoff. $V C$ can reflect the degree of vegetation cover over land area. With increasing $V C$, the amount of sediment in runoff is reduced (Hofmann and Ries 1991). As long as the $V C$ is 
Table 1 Comparison of estimated $K, C F R G$ factors values and previous achievements on them

\begin{tabular}{lllllc}
\hline Soil textural type & Soil textural type & Estimated $K$ & $\begin{array}{l}\text { Estimated } \\
C F R G\end{array}$ & $\begin{array}{l}\text { Multiplier of } \\
\text { estimated } K \text { and } C F R G\end{array}$ & Range of $K$ \\
\hline Clay & Red clay & 0.326 & 0.995 & 0.324 & $0.150-0.423$ \\
Loam & Chestnut soil & 0.357 & 0.996 & 0.356 & $0.006-0.389$ \\
Loamy sand & Alluvial soils & 0.349 & 0.995 & 0.347 & $0.004-0.401$ \\
Sandy loam & Loessal soil & 0.343 & 0.997 & 0.342 & $0.029-0.440$ \\
Sand & Aeolian sandy soil & 0.211 & 0.998 & 0.211 & $0.3-0.4$ \\
\hline
\end{tabular}

Soil textural type (U.S. Department of Agriculture)

Soil textural type (Chinese Soil Database at the Scale of 1:1 M)

Range of $K$ values considering the gravel content calculated by (Shi 2009)

$K$ value observed in July and August in Ansai, Shannxi province by Zhang et al. (2001a, b)

large enough, soil erosion can be controlled whether or not the vegetation is tall forest or low shrub (Jiao and Wang 2001).In order to fully reflect the effect of $V C$ on sediment generation, the cover and management factor $(C)$ is estimated by replacing the method proposed by Wischmeier and Smith (1978) with the formula suggested by Cai et al. (2000).

The $C$ factor proposed by Wischmeier and Smith (1978) is expressed as the Eq. (7):

$$
\begin{aligned}
C= & \exp \left(\left[\ln (0.8)-\ln \left(C_{\mathrm{mm}}\right)\right] \cdot \exp \left[-00115 \cdot r s d_{\text {surf }}\right]\right. \\
& \left.+\ln \left[C_{\mathrm{mm}}\right]\right)
\end{aligned}
$$

where $C_{m m}$ is the minimum value for the cover and management factor for the land cover, and $r s d_{\text {surf }}$ is the amount of residue on the soil surface $(\mathrm{kg} / \mathrm{ha})$.

The revised $C$ factor suggested by Cai et al. (2000) is expressed as the Eq. (8):

$C=\left\{\begin{array}{l}1, \quad c_{v}=0 \\ 0.6508-0.3436 \lg c_{v}, \quad 0<c_{v} \leq 78.3 \% \\ 0, \quad c_{v}>78.3 \%\end{array}\right.$

where $C$ is the cover and management factor, its value is from 0 to 1 . The lower the $C$ value, the more effective the cover and management is deemed to be at reducing soil erosion. $c_{v}$ is vegetation coverage of growing season, or average monthly, quarterly and annual $V C$ (\%). This method had been used to assess the soil erosion control service of ecosystems change (Fu et al. 2011) and the relationship between landscape pattern change and soil erosion (Zhang et al. 2011) in the Loess Plateau.

\subsection{2 $P$, the support practice factor}

In the Loess Plateau, support practice and land use types are closely related. The design of support practice is always dependent on the land use type and is different from that of other regions of the world. Thus, by replacing the method proposed by Wischmeier and Smith
Table $2 P$ factor values for contour-farmed terraced fields (Wischmeier and Smith 1978)

\begin{tabular}{lllllll}
\hline Land slope $(\%)$ & $1-2$ & $3-8$ & $9-12$ & $13-16$ & $17-20$ & $21-25$ \\
\hline Contour $P$ factor & 0.6 & 0.5 & 0.6 & 0.7 & 0.8 & 0.9 \\
Stripcrop $P$ factor & 0.3 & 0.25 & 0.3 & 0.35 & 0.4 & 0.45 \\
\hline
\end{tabular}

(1978) (Table 2), the support practice factor $(P)$ is assigned to different land use classes, referencing the research findings applied in the Loess Plateau of China by Wang and Jiao (1996) (Table 3). If there are no support practices, the $P$ value is 1 . The lower the $P$ value, the more effective the conservation practice is deemed to be at reducing soil erosion.

\subsubsection{LS, the topographic factor}

The topographic factor $(L S)$ was obtained by multiplying the slope length factor $(L)$ and slope gradient factor $(S)$. Considering the large area of Loess Plateau is covered by fragmented topography, and the proportion of steep slope is larger than that in other regions, using the research achievements in the Loess Plateau by Liu et al. (1994, 2000), the $L$ factor and the $S$ factor were revised, respectively.

According to the study of Wischmeier and Smith (1978), the $L S$ factor was calculated as follows:

$L=\left(L_{s l p} / 22.1\right)^{m}\left(65.4 \sin ^{2} \beta+4.56 \sin \beta+0.065\right)$

where $L_{s l p}$ is the slop length $(\mathrm{m}), m$ is the exponential term, and $\beta$ is the angle of the slope. The exponential term, $m$, was calculated:

$m=0.6 \cdot(1-\exp [-35.835 \cdot s l p])$

where $s l p$ is the slope of the grid expressed as rise over run $(\mathrm{m} / \mathrm{m})$. 
Table $3 P$ factor values for different land use classes in Loess Plateau (Wang and Jiao 1996)

\begin{tabular}{llllll}
\hline Land use & $P$ value & Land use & $P$ value & Land use & $P$ value \\
\hline Crop land $\left(\theta<6^{\circ}\right)$ & 0.01 & Open woodland & 1.00 & Water area & 1.00 \\
Crop land $\left(6 \leq \theta<25^{\circ}\right)$ & 0.03 & Spinney & 1.00 & Developed land & 1.00 \\
Crop land $\left(\theta \geq 25^{\circ}\right)$ & 0.30 & Forest & 1.00 & Other land & 1.00 \\
Immature forest land and orchard & 0.20 & Grassland & 1.00 & & \\
\hline
\end{tabular}

$\theta$ is the slope of crop land in degrees

Table 4 Combination of revision of factors

\begin{tabular}{|c|c|c|c|c|c|c|c|}
\hline \multirow[t]{2}{*}{ Combination forms } & \multicolumn{7}{|c|}{ Estimation methods of MUSLE factors } \\
\hline & Rs & $q_{\text {peak }}$ & $K$ & $C F R G$ & $C$ & $P$ & $L S$ \\
\hline \multicolumn{8}{|l|}{ Single factor revised } \\
\hline (a) Original method & Eqs. (2) and (3) & Eq. (4) & Eq. (5) & Eq. (6) & Eq. (7) & Table 1 & Eqs. (9) and (10) \\
\hline (b) Revised $C$ factor & & & & & Eq. (8) & Table 1 & Eqs. (9) and (10) \\
\hline (c) Revised $P$ factor & & & & & Eq. (7) & Table 2 & Eqs. (9) and (10) \\
\hline (d) Revised $L S$ factor & & & & & Eq. (7) & Table 1 & Eqs. (11) and (12) \\
\hline \multicolumn{8}{|l|}{ Two factors revised } \\
\hline (e) Revised $C$ and $\mathrm{P}$ factors & & & & & Eq. (8) & Table 2 & Eqs. (9) and (10) \\
\hline (f) Revised $C$ and $L S$ factors & & & & & Eq. (8) & Table 1 & Eqs. (11) and (12) \\
\hline (g) Revised $P$ and $L S$ factors & & & & & Eq. (7) & Table 2 & Eqs. (11) and (12) \\
\hline \multicolumn{8}{|l|}{ Three factors revised } \\
\hline (h) Revised $C, P$, and $L S$ factors & & & & & Eq. (8) & Table 2 & Eqs. (11) and (12) \\
\hline
\end{tabular}

The revised $L$ factor was calculated as follows (Liu et al. 2000):

$L=\left(L_{s l p} / 22.1\right)^{0.44}$

where $L$ is the slope length factor, $L_{s l p}$ is slope length in meters and 0.44 is the dimensionless exponent.

The revised $S$ factor was derived from three groups as follows (Liu et al. 1994; McCool et al.1987 a):

$S=\left\{\begin{array}{lc}10.8 \sin \theta+0.03, & \theta<5^{\circ} \\ 16.8 \sin \theta-0.5, & 5^{\circ} \leq \theta<10^{\circ} \\ 21.9 \sin \theta-0.96, & \theta>10^{\circ}\end{array}\right.$

where $S$ is the slope gradient factor and is the slope angle in degrees.

\subsection{Combination of revisions to MUSLE factors}

Based on the same estimation methods of $R s, q_{\text {peak }}, K$, and $C F R G$ factors, by revising the estimation methods of $C, P$, and $L S$ factors in three ways(single factor revised, two factors revised, and three factors revised, respectively),there are eight combinations including (a)the original method, (b) the revised $C$ factor, (c) the revised $P$ factor, (d) the revised $L S$ factor, (e) the revised $C$ and $P$ factors, (f) the revised $C$ and $L S$ factors, (g) the revised
$P$ and $L S$ factors, and (h) the revised $C, P$, and $L S$ factors, which were used to estimate sediment yield (Table 4 ).

\subsection{Data preparation}

As mentioned above, the necessary spatial data inputs for MUSLE are: hourly precipitation, DEM data, soil data, land use data, and $V C$ data. Land use and $V C$ data from 1989, 1998, and 2006 were used to represent data for the 1980s, 1990s, and 2000s, respectively.

\subsubsection{Remote sensing data sources}

In the study area, most of the sediment yield is generated during the rainy season, especially July and August, and the rainy season also yields the most crop growth and thus the most $V C$. For this reason, we acquired images during the rainy season to develop the land use and the $V C$ maps. We collected three time series of satellite imagery with a resolution of $30 \mathrm{m:} 3$ August 1989 (Landsat TM 126/32), 2 July 1998 (Landsat TM 127/32), 24 July 2006 (Landsat TM 127/33). Moreover, we used global digital elevation model (GDEM) data at a resolution of $30 \mathrm{~m}$ to extract the topographic information needed for MUSLE, such as the slope length and slope gradient. 


\subsubsection{Precipitation and hydrological data}

Hourly rainfall data was collected from 14 rain-gauge stations (Fig. 1). We collected $100 \mathrm{~h}$ of precipitation data, from August 3 to August 7, 1988 to calibrate the model, and 30 precipitation events (five from the 1980s, nineteen from the 1990s, and six from the 2000s) were used for validation. To interpolate the rainfall data, we used the inverse distance weighted (IDW) method, and we obtained observed discharge and sediment concentration data from Gaoshiya stream gauging station for calibration and validation. Hourly sediment yield was thus calculated by multiplying hourly discharge with sediment concentration.

\subsubsection{Soil properties}

We obtained the soil properties needed for computing soil erodibility and coarse fragment factors from the Chinese national 1:1000,000 scale soil map and the U.S. Department of Agriculture (USDA) classification system for soil texture classes. Under the USDA classification system, the soil in the Gushanchuan basin can be classified in five ways: clay, loam, loamy sand, sandy loam, and sand

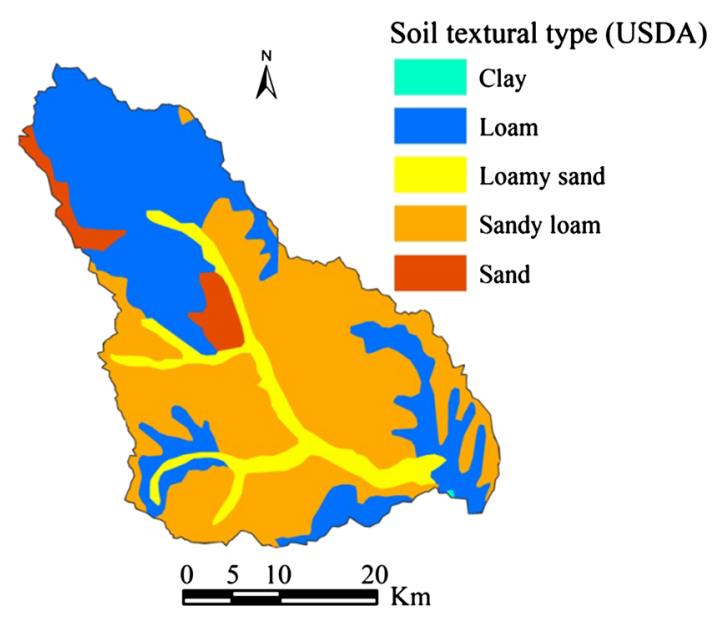

Fig. 3 Soil textural map of Gushanchuan basin
(Fig. 3). The soil types and relevant properties are listed in Table 5.

\subsubsection{Land use classification and accuracy assessment}

According to the land use/cover categories suggested by the Chinese Academy of Sciences and the Chinese national system adopted in 2007 by the Chinese Land Resources Ministry, a man-machine interaction method was employed to extract the land use information, and the land use type was divided into 11 classes based on GDEM data and three time series of Landsat TM imagery. The land use types in the study area were classified as: crop land $\left(\theta<6^{\circ}\right)$, crop land $\left(6 \leq \theta<25^{\circ}\right)$, crop land $\left(\theta \geq 25^{\circ}\right)$, immature forest land and orchard, open woodland, spinney, forest, grassland, water area, developed land, and other land (Fig. 4; Table 6).

We assessed the accuracy of the land use data interpretation with three field verifications. For the 2006 land use data interpretation, we assessed accuracy by visual verification. The results confirmed that 51 out of 57 points were correctly interpreted in 2006, with an accuracy of $89.47 \%$. For the 1998 and 1989 land use data, we used multiple sources of information and multidisciplinary expertise to assess the interpretation accuracy, including referencing historical documents and maps and interviewing local elder residents. The results showed that 46 out of 57 points were correctly interpreted in 1998, with an accuracy of $80.7 \%$, and 42 out of 57 points were correctly interpreted in 1989, with an accuracy of $73.68 \%$.

\subsubsection{Vegetation coverage extracting}

$V C$ was calculated using $N D V I$ derived from Landsat TM images:

$\left\{\begin{array}{l}V C=\left(N D V I-N D V I_{\text {soil }}\right) /\left(N D V I_{\text {veg }}-N D V I_{\text {soil }}\right) \\ N D V I=(N I R-I R) /(N I R+I R)\end{array}\right.$

where $V C$ is vegetation coverage (\%), $N D V I_{\text {soil }}$ is $N D V I$ of bare soil, $N D V I_{v e g}$ refers to the $N D V I$ regional maximum, $N I R$ is the near infrared band, and $I R$ is the infrared band.

Table 5 Soil texture in the Gushanchuan basin

\begin{tabular}{llllllll}
\hline Soil textural type (USDA) & Area $\left(\mathrm{km}^{2}\right)$ & Proportion $(\%)$ & Sand $(\%)$ & Silt $(\%)$ & Clay $(\%)$ & Organic carbon $(\%)$ & Rock $(\%)$ \\
\hline Clay & 0.37 & 0.03 & 23 & 29 & 48 & 1.17 & 10 \\
Loam & 478.00 & 37.58 & 29 & 45 & 26 & 1.42 & 8 \\
Loamy sand & 116.78 & 9.18 & 79 & 15 & 6 & 0.41 & 10 \\
Sandy loam & 626.43 & 49.25 & 76 & 12 & 12 & 0.36 & 5 \\
Sand & 50.42 & 3.96 & 89 & 6 & 5 & 0.50 & 2 \\
\hline
\end{tabular}




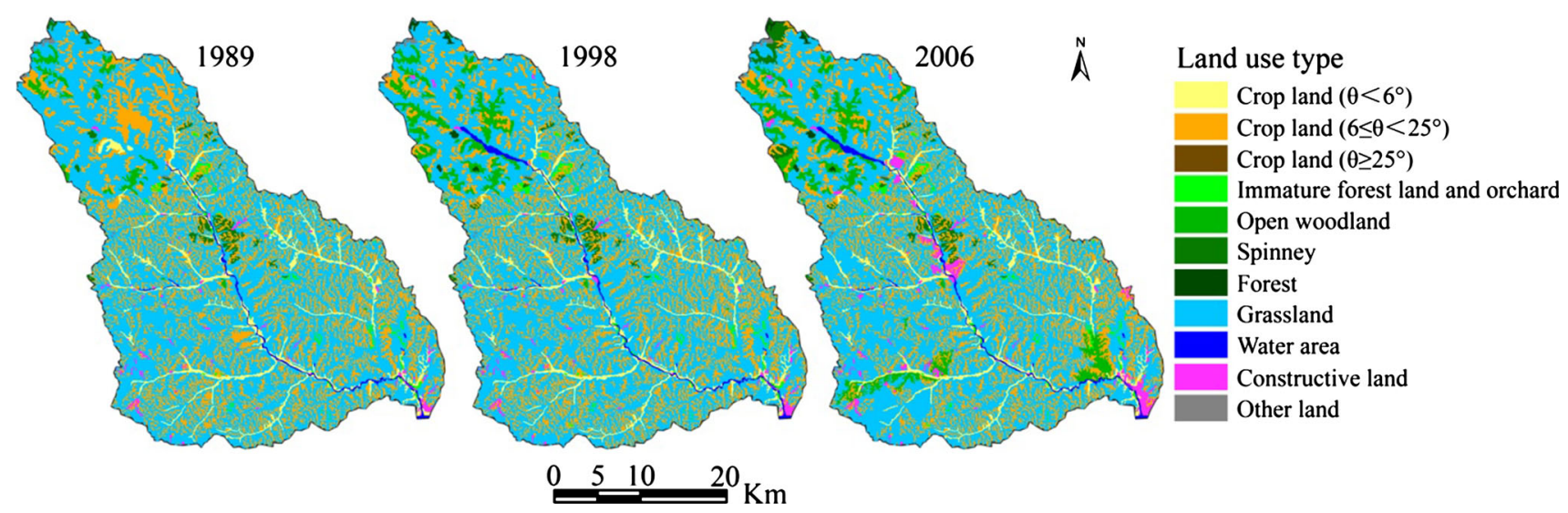

Fig. 4 Land use map of Gushanchuan basin

Table 6 Land use in the Gushanchuan basin

\begin{tabular}{|c|c|c|c|c|c|c|c|}
\hline \multirow[t]{2}{*}{ Land use type } & \multirow[t]{2}{*}{ Description } & \multicolumn{2}{|l|}{1989} & \multicolumn{2}{|l|}{1998} & \multicolumn{2}{|l|}{2006} \\
\hline & & $\mathrm{km}^{2}$ & $\%$ & $\mathrm{~km}^{2}$ & $\%$ & $\mathrm{~km}^{2}$ & $\%$ \\
\hline Crop land $\left(\theta<6^{\circ}\right)$ & Cultivated land for agriculture on a slope less than $6^{\circ}$ & 58.68 & 4.61 & 53.82 & 4.23 & 53.82 & 4.23 \\
\hline Crop land $\left(6 \leq \theta<25^{\circ}\right)$ & Cultivated land for agriculture on a $6^{\circ}-25^{\circ}$ slope & 346.26 & 27.22 & 327.47 & 25.74 & 314.35 & 24.71 \\
\hline Crop land $\left(\theta \geq 25^{\circ}\right)$ & Cultivated land for agriculture on a slope greater than $25^{\circ}$ & 4.73 & 0.37 & 2.95 & 0.23 & 0.00 & 0.00 \\
\hline $\begin{array}{l}\text { Immature forest } \\
\text { land and orchard }\end{array}$ & Lands dominated by immature trees & 9.94 & 0.78 & 11.84 & 0.93 & 11.31 & 0.89 \\
\hline Open woodland & Lands dominated by trees with a canopy cover of $10-20 \%$ & 18.51 & 1.46 & 46.44 & 3.65 & 69.26 & 5.44 \\
\hline Spinney & Lands with woody vegetation less than 2 meters & 14.22 & 1.12 & 12.24 & 0.96 & 21.38 & 1.68 \\
\hline Forest & Lands dominated by trees with a canopy cover over $20 \%$ & 0.00 & 0.00 & 2.11 & 0.17 & 2.79 & 0.22 \\
\hline Grassland & Lands with herbaceous types with a canopy cover over $5 \%$ & 798.8 & 62.80 & 788.99 & 62.03 & 759.26 & 59.69 \\
\hline Water area & Lakes, reservoirs, and rivers. & 9.15 & 0.72 & 13 & 1.02 & 13 & 1.02 \\
\hline Developed land & Land covered by buildings and other man-made structures & 10.05 & 0.79 & 11.48 & 0.90 & 25.9 & 2.04 \\
\hline Other land & $\begin{array}{l}\text { Land with exposed soil and stone with a } \\
\text { vegetated cover of less than } 5 \%\end{array}$ & 1.66 & 0.13 & 1.66 & 0.13 & 0.93 & 0.07 \\
\hline
\end{tabular}

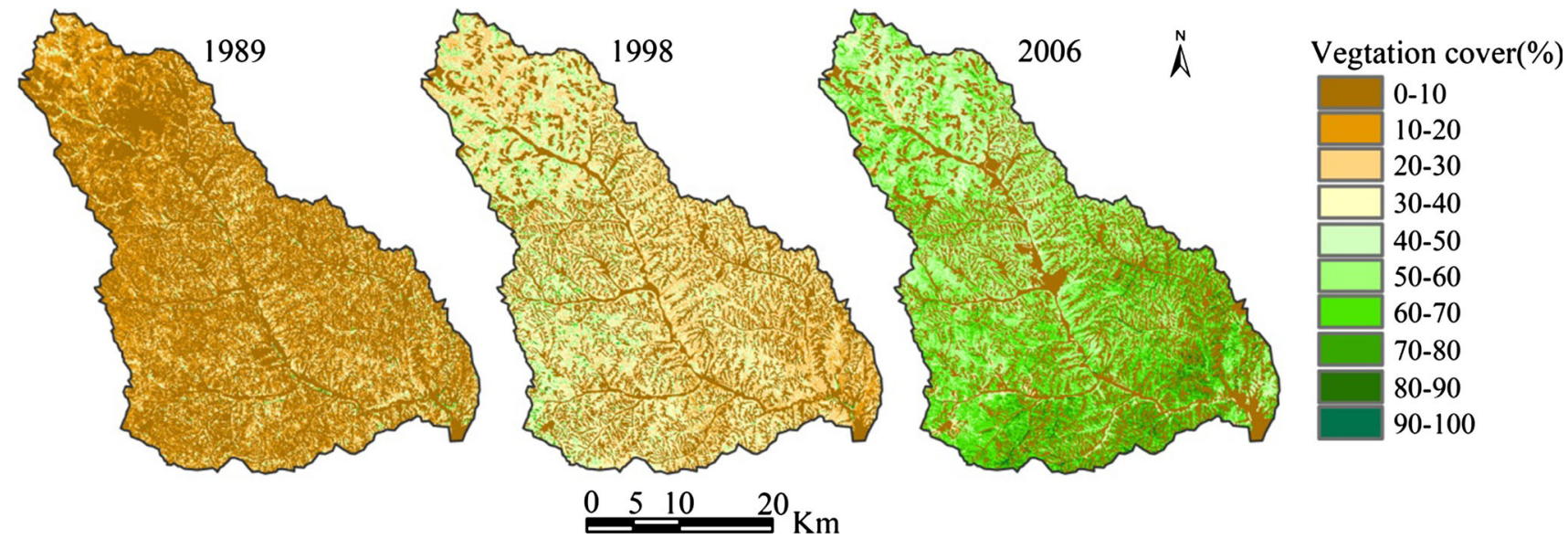

Fig. 5 Vegetation coverage map of Gushanchuan basin 
Table 7 Vegetation coverage in the Gushanchuan basin

\begin{tabular}{|c|c|c|c|c|c|c|}
\hline \multirow[t]{2}{*}{ Vegetation coverage $(\%)$} & \multicolumn{2}{|l|}{1989} & \multicolumn{2}{|l|}{1998} & \multicolumn{2}{|l|}{2006} \\
\hline & $\mathrm{km}^{2}$ & $\%$ & $\mathrm{~km}^{2}$ & $\%$ & $\mathrm{~km}^{2}$ & $\%$ \\
\hline $0-10$ & 668.00 & 52.52 & 409.83 & 32.22 & 405.99 & 31.92 \\
\hline $10-20$ & 307.30 & 24.16 & 29.41 & 2.31 & 1.26 & 0.10 \\
\hline $20-30$ & 194.46 & 15.29 & 299.80 & 23.57 & 5.06 & 0.40 \\
\hline $30-40$ & 68.50 & 5.39 & 332.55 & 26.14 & 19.98 & 1.57 \\
\hline $40-50$ & 22.49 & 1.77 & 129.70 & 10.20 & 125.92 & 9.90 \\
\hline $50-60$ & 6.97 & 0.55 & 47.75 & 3.75 & 346.73 & 27.26 \\
\hline $60-70$ & 2.59 & 0.20 & 16.09 & 1.26 & 266.19 & 20.93 \\
\hline $70-80$ & 1.04 & 0.08 & 5.00 & 0.39 & 83.58 & 6.57 \\
\hline $80-90$ & 0.41 & 0.03 & 1.41 & 0.11 & 14.50 & 1.14 \\
\hline 90-100 & 0.26 & 0.02 & 0.47 & 0.04 & 2.77 & 0.22 \\
\hline
\end{tabular}

The values of $V C$ were calculated with a range from 0 to $100 \%$ (Fig. 5; Table 7).

\subsection{Model performance evaluation criteria}

Three common statistical criteria were used to measure the agreement between estimated and observed values of runoff and sediment yield. A good agreement indicates a good model performance, and vice versa.

$$
\begin{aligned}
& \mathrm{NSE}=1-\sum_{i=1}^{N}\left(O_{i}-E_{i}\right)^{2} / \sum_{i=1}^{N}\left(O_{i}-\bar{O}\right)^{2} \\
& \mathrm{NRMSE}=\sqrt{\frac{1}{N} \sum_{i=1}^{N}\left(O_{i}-E_{i}\right)^{2} / \bar{O}} \\
& \mathrm{R}=\left(\sum_{i=1}^{N}\left(O_{i}-\bar{O}\right)\left(E_{i}-\bar{E}\right)\right) / \\
& \left(\sqrt{\frac{1}{N} \sum_{i=1}^{N}\left(O_{i}-\bar{O}\right)^{2}} \sqrt{\frac{1}{N} \sum_{i=1}^{N}\left(E_{i}-\bar{E}\right)^{2}}\right)
\end{aligned}
$$

where NSE is the Nash-Sutcliffe coefficient of efficiency (Nash and Sutcliffe 1970), NRMSE is the normalized rootmean-square error, $R$ is the Pearson product-moment correlation coefficient, $O_{i}$ is observed runoff or sediment yield, $E_{i}$ is estimated runoff or sediment yield, $\bar{O}$ is the average observed runoff or sediment, $N$ is the total number of records for comparison and $\bar{E}$ is the average estimated runoff or sediment. NSE $=1$ represents the best model performance, and decreasing values indicate poor agreement between observed and estimated values. A lower NRMSE value indicates better model performance. A higher $\mathrm{R}$ value indicates better model performance.

Furthermore, in order to evaluate model performance on sediment peak estimation, a scatter plot was drawn to show the linear relationship between observed and simulated values. The angle between the linear trend line and the $1: 1$ line of the scatter plot was used to indicate the model performance on sediment peak estimation. A smaller angle indicates a better model performance. Meanwhile, if the linear trend line is located above the 1:1 line then the sediment peak is overestimated, and vice versa.

\section{Results and discussion}

\subsection{Estimation results of surface runoff}

The accuracy of the sediment yield estimation is highly dependent on the hydrological results, particularly when the surface runoff is treated as an independent factor in both the soil erosion stage and the sediment transport stage (Wang et al. 2012).The estimated cumulative discharge at the outlet of the basin was compared with the observed data to evaluate the accuracy of surface runoff simulation (Fig. 6). As shown in Fig. 6, the estimated discharge matches the observed values well $\left(\mathrm{R}^{2}=0.851\right)$, and the NSE and the NRMSE values are 0.85 and 0.77 ,

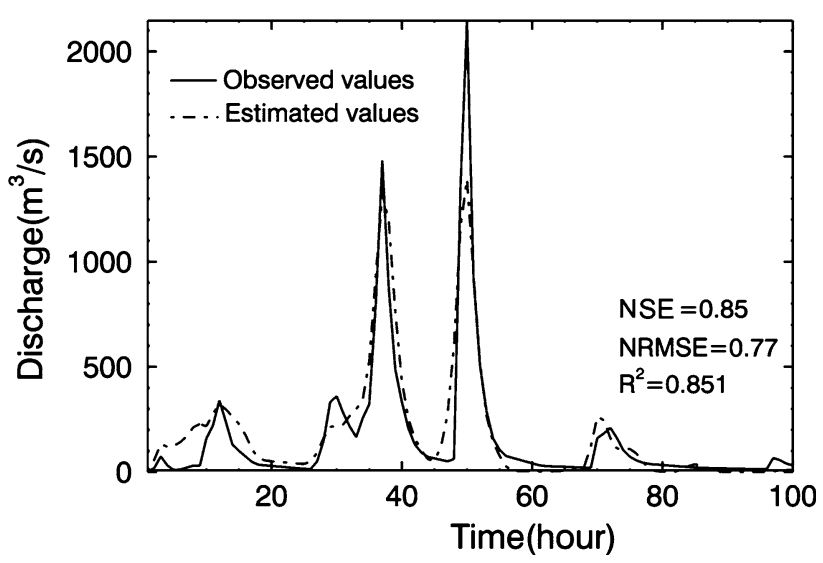

Fig. 6 Comparison between estimated and observed discharge 
Table 8 Comparison between estimated and observed sediment yield modulus for different combinations

\begin{tabular}{|c|c|c|c|}
\hline \multirow[t]{2}{*}{ Combination } & \multicolumn{2}{|c|}{ Sediment yield modulus $\left(\mathrm{t} \mathrm{km}^{-2} \mathrm{~h}^{-1}\right)$} & \multirow[t]{2}{*}{ Deviation $(\%)$} \\
\hline & Observed & Estimated & \\
\hline \multicolumn{4}{|l|}{ Single factor revised } \\
\hline (a) Original method & 216 & 524 & 142.59 \\
\hline (b) Revised $C$ factor & & 428 & 98.15 \\
\hline (c) Revised $P$ factor & & 415 & 92.13 \\
\hline (d) Revised $L S$ factor & & 363 & 68.06 \\
\hline \multicolumn{4}{|l|}{ Two factors revised } \\
\hline (e) Revised $C$ and $P$ factors & & 325 & 50.46 \\
\hline (f) Revised $C$ and $L S$ factors & & 290 & 34.26 \\
\hline \multicolumn{4}{|l|}{ Three factors revised } \\
\hline (g) Revised $P$ and $L S$ factors & & 281 & 30.09 \\
\hline (h) Revised $C, P$ and $L S$ factors & & 220 & 1.85 \\
\hline
\end{tabular}

respectively. The result shows that the estimated surface runoff can be used as an input for MUSLE to predict the sediment yield of the study area.

\subsection{Estimation results of sediment yield}

Because of the availability of input data, sediment yield was simulated at a one-hour time step. Syncing with runoff, sediment yield generation in every grid was routed to the outlet. The estimated and observed sediment yield modulus for different combinations is compared and shown in Table 8 . The result shows that the original method significantly overestimates the sediment yield with a deviation of $142.59 \%$. By revising the estimated methods of factors $C$, $P$, and $L S$, the estimating results were increasingly satisfactory. When a single factor is revised, the deviation drops from 98.15 to $68.06 \%$. In the cases when two factors are revised, the deviation also drops, from 50.46 to $30.09 \%$. When $C, P$, and $L S$ factors are revised simultaneously, the minimum deviation is obtained with a value of $1.85 \%$.

\subsection{General accuracy of different combinations on sediment yield estimation}

The sediment yield of tributaries is a key factor for Yellow River basin planning. General accuracy verification is an important measure to evaluate the suitability of MUSLE for estimating sediment yield of rainfall events (Fig. 7a-h; Table 9).

First, no matter how many factors of $C, P$, and $L S$ get revised, the correlation coefficient has no obvious change, with $\mathrm{R}^{2}$ values ranging from 0.746 to 0.760 . This result indicates that the correlation between simulated and observed values is not influenced remarkably by the revision.

Second, when revising the $C, P$, and $L S$, respectively, the effect of the $L S$ factor revision on the estimating accuracy is the best of all (Fig. 6b-d). The NSE value of the combination (d) is 0.46 . Accordingly, the NSE values in combinations (b) and (c) are 0.06 and 0.13 , respectively. The NSE value of the combination (d) is $0.40,0.33$ higher than the combinations (b) and (c).This result indicates that if only one factor can be revised when there are limited data, the $L S$ factor ought to have a priority to the extent possible.

Finally, the more factors get revised, the better general accuracy of MUSLE performance. In the cases where a single factor is revised, the NSE values of the combinations (b) (Fig. 6b), (c) (Fig. 6c), and (d) (Fig. 6d) are 0.06, 0.13 , and 0.46 , which are $0.96,1.03$, and 1.36 higher than the original method, respectively. In the cases in which two factors are revised, the NSE values of the combinations (e) (Fig. 6e), (f) (Fig. 6f), and (g) (Fig. 6g) are 0.56, 0.70 , and 0.72 , which are $1.46,1.60$, and 1.62 higher than the original method, respectively. When the $C, P$, and $L S$ factors are revised simultaneously (Fig. 6h), the NSE value is 0.76 , which is 1.66 higher than the original method. At the same time, it is also true that the NRMSE value declines by revising the $C, P$, and $L S$ factors. This result indicates that the general accuracy of the combination (h) is best, and is useful to estimate sediment yield of rainfall event.

\subsection{Effect of different combinations on sediment peak estimation}

Accurate estimation of sediment peak is useful for flood disaster assessment. The angle between the linear trend line and the 1:1 line of a scatter plot was used to reflect the effect of sediment peak estimation in Fig. $8 \mathrm{a}-\mathrm{h}$.

First, Fig. 8a-d clearly show that all trend lines are located above the 1:1 lines, and the angles between linear trend and $1: 1$ lines are $15.13^{\circ}, 8.97^{\circ}, 8.19^{\circ}$, and $4.31^{\circ}$, respectively. This result indicates that although all of the 

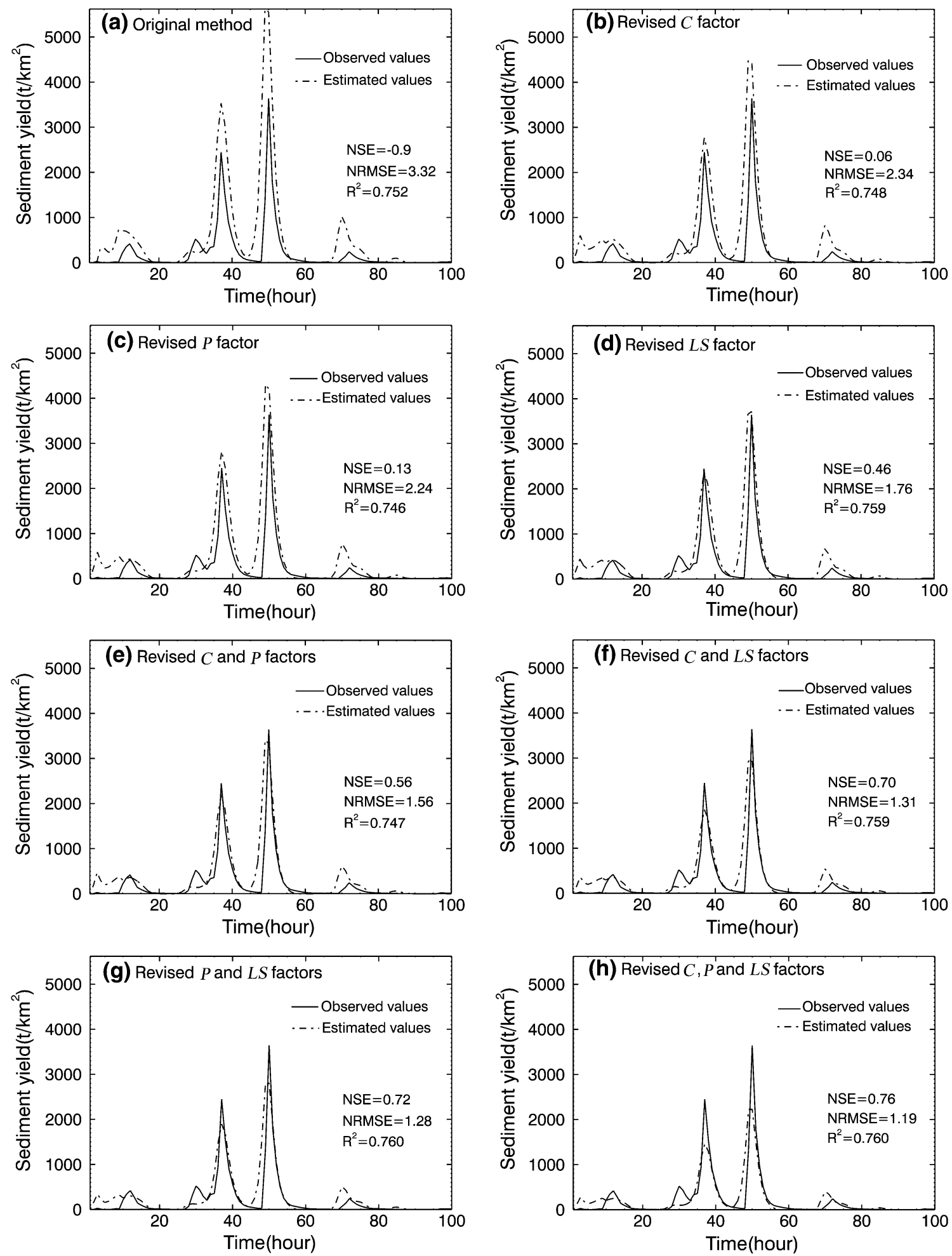

Fig. 7 Comparison between estimated and observed sediment yield

four combinations including the combinations (a), (b), (c), and (d) significantly overestimate the sediment peak, the overestimation is diminishing.
Second, from Fig. 8e, it can be seen that the estimated sediment peak of the combination (e) is consistent with the observed value, having a trend line close to the 1:1 line, 
Table 9 Values of model performance evaluation criteria for different combinations

\begin{tabular}{lrll}
\hline Combination & NSE & NRMSE & $\mathrm{R}^{2}$ \\
\hline Single factor revised & & & \\
(a) Original method & -0.90 & 3.32 & 0.752 \\
(b) Revised $C$ factor & 0.06 & 2.34 & 0.748 \\
(c) Revised $P$ factor & 0.13 & 2.24 & 0.746 \\
(d) Revised $L S$ factor & 0.46 & 1.76 & 0.759 \\
Two factors revised & & & \\
(e) Revised $C$ and $P$ factors & 0.56 & 1.56 & 0.747 \\
(f) Revised $C$ and $L S$ factors & 0.70 & 1.31 & 0.759 \\
Three factors revised & & & \\
(g) Revised $P$ and $L S$ factors & 0.72 & 1.28 & 0.760 \\
(h) Revised $C, P$ and $L S$ factors & 0.76 & 1.19 & 0.760 \\
\hline
\end{tabular}

and the better performance of the combination is supported by a smaller angle, which is $1.37^{\circ}$. This result shows that the sediment peak can be better estimated based on the combination (e).

Finally, as shown in Figs. $8 \mathrm{f}-\mathrm{h}$, the trend lines of combinations (f) and (h) are located under the 1:1 lines, with angles of $2.23^{\circ}$ and $9.78^{\circ}$, respectively. This result indicates that the three models significantly underestimate the sediment peak and may not be appropriate for simulating the sediment peak.

\subsection{Suitability of revision to MUSLE}

The suitability of MUSLE is closely related to the combination method used for its factor evaluation. From Sects. 3.3 and 3.4, we inferred that the combination (h) can be used to estimate sediment yield and the combination (e) can be used to estimate sediment peak, respectively. Thirty events (five in the 1980s, nineteen in the 1990s and six in the 2000s) were used to validate this inference. Table 10 and Fig. 9 compare estimated sediment yield based on combination (h) with estimated sediment peak based on combination (e) for 30 validation events of observed data and lists the relevant deviations.

For the sediment yield estimations based on the combination (h), the deviations of five events in the 1980s range between -47.22 and $34.39 \%$, the deviations of nineteen events in the 1990s range between -53.54 and $47.96 \%$, and the deviations of six events in the 2000s range between -58.58 and $382.68 \%$. The estimated sediment yields of 30 validation events are plotted against the observations in Fig. 8a, and the trend line shows a statistical fit of $\mathbf{R}^{2}=0.81$.

For the sediment peak estimations based on the combination (e), the deviations of five events in the 1980s range between -43.42 and $34.89 \%$, the deviations of nineteen events in the 1990s range between -51.78 and $48.55 \%$, and the deviations of six events in the 2000s range between -63.75 and $2127.39 \%$. The estimated sediment peaks of 30 validation events are plotted against the observations in Fig. $8 \mathrm{~b}$, and the trend line shows a statistical fit of $\mathrm{R}^{2}=0.90$.

Bingner et al. (1989) posited that if the underestimation or overestimation of soil erosion was within $20 \%$ of the observed values, the simulation could be considered acceptable. For the 30 validation events, Table 10 shows that the average deviations of sediment yield and sediment peak estimations are -0.96 and $0.11 \%$ for the $1980 \mathrm{~s}$, -13.02 and $-10.08 \%$ for the $1990 \mathrm{~s}$, and 111.93 and $361.45 \%$ for the 2000s, respectively; this shows that the average sediment yield and sediment peak estimations in the 1980s and 1990s are within acceptable levels. Table 11 shows the respective percentages of deviation less than $20 \%$ for sediment yield and sediment peak estimations for the three decades: 60 and $60 \%$ in the 1980s, 36.84 and $42.11 \%$ in the $1990 \mathrm{~s}, 33.33$ and $16.67 \%$ in the 2000s. The results indicate that combination (h) and combination (e) produce reasonable estimations of sediment yield and sediment peak in the 1980s and 1990s, and give significant over-estimations of sediment yield and sediment peak in the 2000s.

The difficulty of extracting the level terrace using Landsat TM data at a resolution of $30 \mathrm{~m}$ is the major cause of sediment yield and sediment peak overestimation in the 2000s. In the Loess Plateau, land terracing has been an important measure for soil and water conservation since the Grain to Green Program (GTGP) launched in 1999 (Lu et al. 2009). According to local government statistical data, few level terraces were distributed in the study area before 1998; between 2000 and 2012, about $38 \mathrm{~km}^{2}$ (2.98\% of study area) of man-made level terrace was built on the most severely eroded slope farmlands to decrease soil erosion and improve agricultural productivity. Level terraces can not only reduce more than $95 \%$ of the sediment yield (Jiao et al. 1999), but they also intercept the sediment yield from the upper regions (Liu et al. 2014). Most of the level terraces are built on the hill-slopes of more than $6^{\circ}$ and their surface widths are usually narrower than $15 \mathrm{~m}$ (Fig. 10), and are difficult to identify using the $30 \mathrm{~m}$ resolution remote sensing images. Due to the lack of spatial information for level terrace distribution, the result for the estimated support practice factor $(P)$ value is greater than the actual value, thus significantly overestimating sediment yield and sediment peak for the 2000s.

We therefore suggest that when accurate level terrace spatial information can be obtained or when there are few level terraces, combination (h) is a more accurate method for estimating sediment yield. Furthermore, combination 
Fig. 8 Effect of different factor's revision on sediment peak estimation
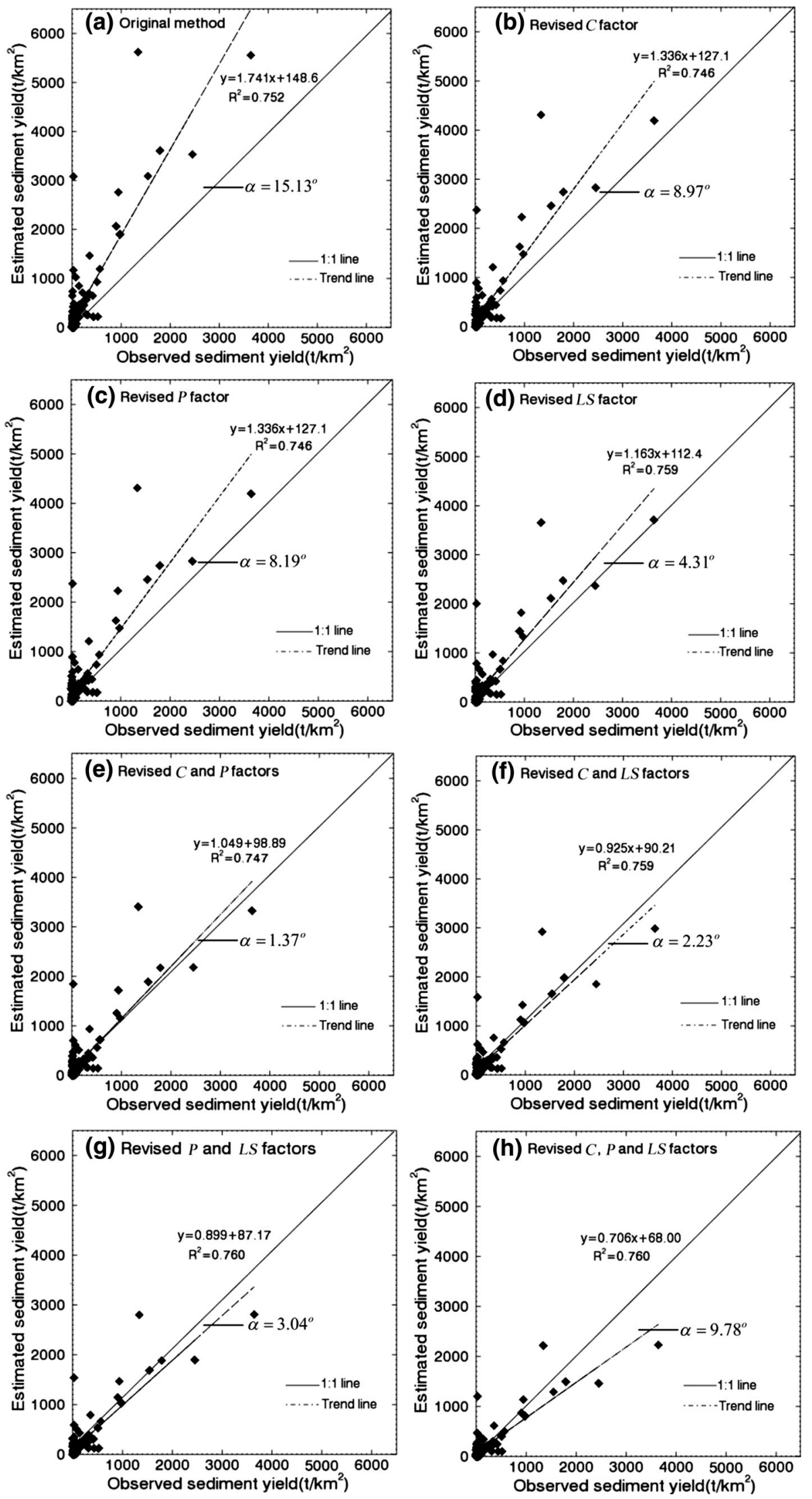
Table 10 Observed and estimated sediment yield and sediment peak for 30 validation events based on combination (h) and combination (e), respectively

\begin{tabular}{|c|c|c|c|c|c|c|c|c|c|}
\hline \multirow[t]{2}{*}{ Times } & \multirow[t]{2}{*}{$\begin{array}{l}\text { Date } \\
\text { (Year/month/day) }\end{array}$} & \multicolumn{4}{|c|}{$\begin{array}{l}\text { Observed and estimated sediment yields based on the } \\
\text { combination (h) }\end{array}$} & \multicolumn{4}{|c|}{$\begin{array}{l}\text { Observed and estimated sediment peaks based on the } \\
\text { combination (e) }\end{array}$} \\
\hline & & $\begin{array}{l}\text { Observed } \\
\left(10^{4} \mathrm{t}\right)\end{array}$ & $\begin{array}{l}\text { Estimated } \\
\left(10^{4} \mathrm{t}\right)\end{array}$ & $\begin{array}{l}\text { Deviation } \\
(\%)\end{array}$ & $\begin{array}{l}\text { Average } \\
\text { deviation }(\%)\end{array}$ & $\begin{array}{l}\text { Observed } \\
\left(10^{4} \mathrm{t}\right)\end{array}$ & $\begin{array}{l}\text { Estimated } \\
\left(10^{4} \mathrm{t}\right)\end{array}$ & $\begin{array}{l}\text { Deviation } \\
(\%)\end{array}$ & $\begin{array}{l}\text { Average } \\
\text { deviation }(\%)\end{array}$ \\
\hline \multirow[t]{5}{*}{$1980 \mathrm{~s}$} & $1985 / 07 / 09$ & 176.32 & 154.49 & 12.38 & -0.96 & 68.61 & 38.82 & -43.42 & 0.11 \\
\hline & $1985 / 08 / 04$ & 178.51 & 159.36 & 10.73 & & 83.99 & 74.88 & -10.84 & \\
\hline & $1986 / 08 / 06$ & 93.53 & 79.43 & -15.07 & & 34.90 & 40.28 & 15.41 & \\
\hline & $1989 / 07 / 22$ & 432.67 & 228.37 & -47.22 & & 150.54 & 98.02 & 34.89 & \\
\hline & $1989 / 07 / 24$ & 292.97 & 393.73 & 34.39 & & 83.66 & 87.44 & 4.51 & \\
\hline \multirow[t]{19}{*}{ 1990s } & $1992 / 07 / 29$ & 460.79 & 439.93 & -4.53 & -13.02 & 70.89 & 65.19 & -8.47 & -10.08 \\
\hline & 1990/08/01 & 54.51 & 29.12 & -46.58 & & 13.08 & 15.69 & 19.95 & \\
\hline & $1992 / 07 / 25$ & 245.58 & 363.36 & 47.96 & & 95.07 & 96.39 & 1.39 & \\
\hline & $1992 / 07 / 27$ & 379.10 & 213.16 & -43.77 & & 81.10 & 78.52 & -3.19 & \\
\hline & $1992 / 08 / 05$ & 51.41 & 47.48 & -7.65 & & 16.36 & 10.73 & -34.41 & \\
\hline & $1992 / 08 / 11$ & 609.65 & 766.60 & 25.74 & & 285.69 & 251.38 & -12.01 & \\
\hline & $1993 / 07 / 08$ & 82.88 & 102.16 & 23.26 & & 36.69 & 52.59 & 43.34 & \\
\hline & $1994 / 07 / 07$ & 1013.66 & 868.41 & -14.33 & & 290.85 & 203.24 & -30.12 & \\
\hline & $1994 / 07 / 26$ & 276.26 & 128.35 & -53.54 & & 81.52 & 50.90 & -37.56 & \\
\hline & $1994 / 08 / 04$ & 108.72 & 56.90 & -47.66 & & 56.65 & 29.15 & 48.55 & \\
\hline & $1994 / 08 / 10$ & 99.97 & 96.40 & -3.57 & & 41.47 & 38.55 & -7.04 & \\
\hline & $1994 / 08 / 14$ & 104.11 & 53.56 & -48.56 & & 14.52 & 7.01 & -51.78 & \\
\hline & $1995 / 08 / 12$ & 47.96 & 27.13 & -43.44 & & 9.92 & 8.49 & -14.40 & \\
\hline & $1996 / 07 / 16$ & 177.85 & 152.21 & 14.42 & & 58.07 & 39.89 & -31.31 & \\
\hline & $1996 / 08 / 11$ & 690.34 & 566.25 & -17.98 & & 109.76 & 130.53 & 18.92 & \\
\hline & $1997 / 07 / 30$ & 383.37 & 357.37 & -6.78 & & 173.54 & 132.41 & -23.70 & \\
\hline & 1997/08/01 & 219.88 & 324.03 & 47.37 & & 90.29 & 113.55 & 25.76 & \\
\hline & $1998 / 07 / 13$ & 292.55 & 197.67 & -32.43 & & 111.46 & 56.49 & -49.32 & \\
\hline & $1998 / 07 / 18$ & 61.38 & 39.76 & -35.22 & & 20.34 & 10.95 & -46.18 & \\
\hline \multirow[t]{6}{*}{$2000 \mathrm{~s}$} & $2000 / 08 / 16$ & 78.95 & 32.70 & -58.58 & 111.93 & 36.40 & 13.20 & -63.75 & 361.45 \\
\hline & $2001 / 07 / 25$ & 220.35 & 247.50 & 12.32 & & 89.94 & 48.52 & -46.05 & \\
\hline & $2002 / 07 / 20$ & 63.43 & 56.63 & -10.73 & & 10.08 & 14.92 & 48.06 & \\
\hline & $2003 / 07 / 08$ & 18.18 & 69.21 & 280.72 & & 11.08 & 22.15 & 99.80 & \\
\hline & $2003 / 07 / 30$ & 651.20 & 1074.76 & 65.14 & & 267.27 & 275.87 & 3.22 & \\
\hline & $2009 / 09 / 24$ & 10.31 & 49.74 & 382.68 & & 0.82 & 18.26 & 2127.39 & \\
\hline
\end{tabular}

Fig. 9 Comparison of the observed and estimated sediment yield and sediment peak for the 30 events a sediment yield b sediment peak
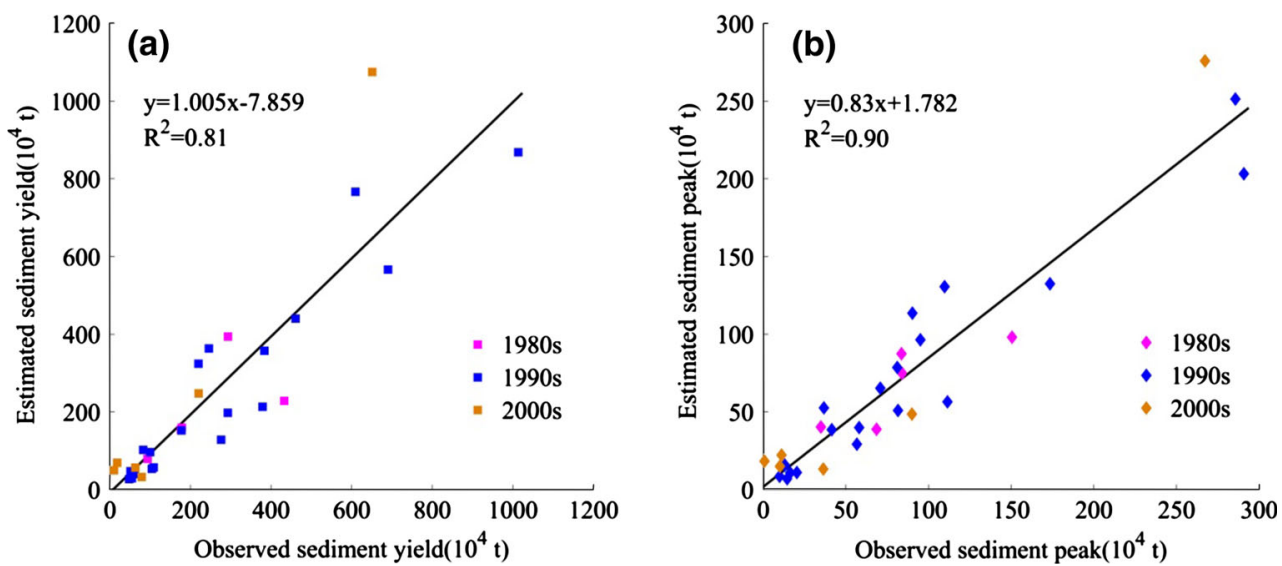
Table 11 Percentage of deviation less than $20 \%$ of sediment yield and sediment peak estimations for 30 validation events

\begin{tabular}{|c|c|c|c|c|c|}
\hline \multirow[t]{2}{*}{ Times } & \multirow[t]{2}{*}{ Events amount } & \multicolumn{2}{|c|}{ Deviation less than $20 \%$ (sediment yield estimation) } & \multicolumn{2}{|c|}{ Deviation less than $20 \%$ (sediment peak estimation) } \\
\hline & & Amount & Percentage $(\%)$ & Amount & Percentage $(\%)$ \\
\hline $1980 \mathrm{~s}$ & 5 & 3 & 60.00 & 3 & 60.00 \\
\hline $1990 \mathrm{~s}$ & 19 & 7 & 36.84 & 8 & 42.11 \\
\hline $2000 \mathrm{~s}$ & 6 & 2 & 33.33 & 1 & 16.67 \\
\hline
\end{tabular}

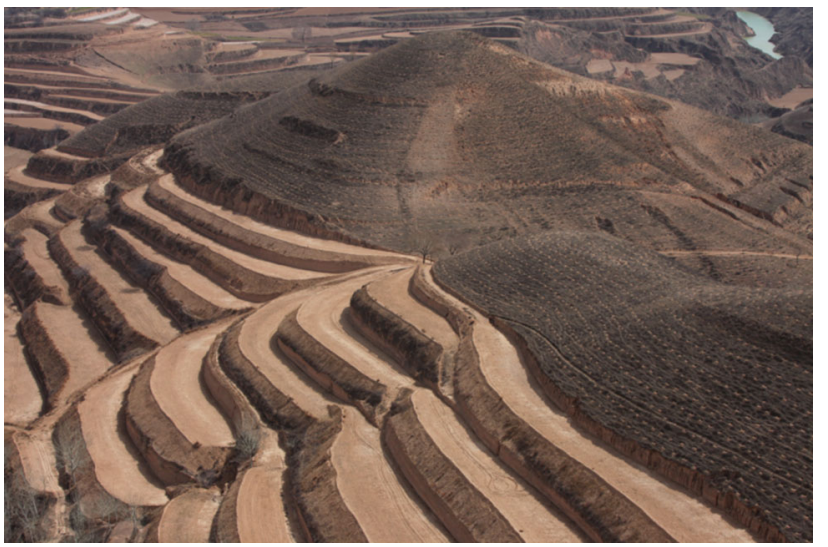

Fig. 10 The level terraces

(e) can be used when estimating accuracy of sediment peak is needed, as it better describes the sediment peak.

\section{Conclusions}

In this study, we examined the effects of revisions to cover and management $(C)$, support practice $(P)$, and topographic $(L S)$ factors for MUSLE on sediment yield estimation in the Loess Plateau. The MUSLE performance improved at different levels, based on the combination of these factors in three ways (single factor revised, two factors revised and three factors revised, respectively). The effects differed in different revision combinations to the MUSLE factors. The original method significantly overestimates the sediment yield. When revising a single factor, the $L S$ factor revision has the greatest positive effect. When revising two factors, the combination of a simultaneous revision to $C$ and to $P$ has the smallest angle between the liner trend line and the $1: 1$ line $\left(1.37^{\circ}\right)$; if the estimating accuracy of sediment peak is required, this combination may thus be a useful approach. When revising $C, P$, and $L S$ simultaneously, the combination has the highest NSE (0.76), lowest NRMSE (1.19), and the highest correlation coefficient (0.760), and may be used to estimate sediment yield. Furthermore, the suitability of MUSLE is enhanced using the common local revision to factors $C, P$, and $L S$. Under the assumption that level terrace spatial information can obtain effectively (or that there are few level terraces), these findings can be applied to the Loess Plateau for the design of soil and water conservation measures and for flood disaster assessment, and applied to future model applications in the Loess Plateau.

Acknowledgments This research was financially supported by the National Key Technologies R\&D Program (Grant No. 2012BAB02B00), Public Welfare Foundation of the Ministry of Water Resources of China (Grant No. 201101037), the Fundamental Research Funds for the Central Universities, National Natural Science Foundation of China (Grant No. 41301496). We are very grateful to the reviewers for their constructive comments and thoughtful suggestions.

\section{References}

ASCE (American Society of Civil Engineering) (1970) Sediment sources and sediment yield. In Proceedings of ASCE, J Hydraul Div 6:1283-1329

Bingner RL, Murphee CE, Mutchler CK (1989) Comparison of sediment yield models on various watershed in Mississippi. Trans Am Soc Agric Eng 32:529-534

Cai CF, Ding SW, Shi ZH, Huang L, Zhang GY (2000) Study of applying USLE and geographical information system IDRISI to predict soil erosion in small watershed. J Soil Water Conserv 14(2):19-24 (in Chinese)

Fu BJ, Liu Y, Lü YH, He CS, Zeng Y, Wu BF (2011) Assessing the soil erosion control service of ecosystems change in the Loess Plateau of China. Ecol Complex 8:284-293

Gao GY, Fu BJ, Lü YH, Liu Y, Wang S, Zhou J (2012) Coupling the modified SCS-CN and RUSLE models to simulate hydrological effects of restoring vegetation in the Loess Plateau of China. Hydrol Earth Syst Sci 16:2347-2364

Gates JB, Scanlon BR, Mu XM, Zhang L (2011) Impacts of soil conservation on groundwater recharge in the semi-arid Loess Plateau, China. Hydro geol J 19(4):865-875

Hofmann L, Ries RE (1991) Relationship of soil and plant characteristics to erosion and runoff on pasture and range. J Soil Water Conserv 46(2):143-147

Jain SK, Tyagi J, Singh V (2010) Simulation of runoff and sediment yield for a Himalayan watershed using SWAT model. J Water Resour Prot 2:267-281

Jiang D (1978) Study on erodibility of loess. Bull Soil Sci. 4:20-23 (in Chinese)

Jiang D, Zhu X (1962) Soil and water conservation. In: Soil Fertilizer Institute of Chinese Academy of Agriculture and Committee (ed) Proceedings of Chinese agricultural soils on compiling chinese agricultural soils. Shanghai Science and Technology Press, Shanghai (in Chinese) 
Jiao JY, Wang WZ (2001) The benefits of runoff and sediment reducing \& effective cover rate for soil and water conservation of artificial grassland on Loess Plateau. Acta Agrestia Sinica 9(3): 176-182 (in Chinese)

Jiao JY, Wang WZ, Li J (1999) Analysis on soil and water conservation benefit of level terrace under different rainfall condition in loess hilly region. J Soil Erosion Soil Water Conserv 5:59-63 (In Chinese)

Lal R (2003) Soil erosion and the global carbon budget. Environ Int 29(4):437-450

Li Y, Wu QX, Zhu XM, Tian JY (1990) A study on soil antiscourability increased by root system of plant in the Loess Plateau. Acta Coserv Soli Et Aquae Sin 4(1):1-5 (in Chinese)

Liang K, Liu CM, Liu XM, Song XF (2013) Impacts of climate variability and human activity on streamflow decrease in a sediment concentrated region in the Middle Yellow River. Stoch Environ Res Risk Assess 27:1741-1749

Liu CM, Hong BX, Zeng MX, Cheng Y (1965) Experimental study on the relationship between storm and runoff in the Loess Plateau of China. Chin Sci Bull 2:158-161 (in Chinese)

Liu BY, Nearing MA, Risse LM (1994) Slope gradient effects on soil loss for steep slopes. T ASAE 37(6):1835-1840

Liu BY, Nearing MA, Shi PJ, Jia ZW (2000) Slope length effects on soil loss for steep slopes. Soil Sci Soc Am J 64:1759-1763

Liu CM, Wang ZG, Zheng HX, Zhang L, Wu XF (2008) Development of hydro-informatic modelling system and its application. Sci China Ser E 51(4):456-466

Liu XY, Wang FG, Yang ST, Li XY, He XZ, Ma HB (2014) Sediment reduction effect of level terrace in the hilly-gully region in the Loess Plateau. J Hydraul Eng 45(7):793-800 (In Chinese)

Lu HS, Zhu YH, Skaggs TH, Yu ZB (2009) Comparison of measured and simulated water storage in dryland terraces of the Loess Plateau, China. Agric Water Manage 96:299-306

Lü YH, Fu BJ, Feng XM, Zeng Y, Liu Y, Chang RY, Sun G, Wu BF (2012) A policy-driven large scale ecological restoration: quantifying ecosystem services changes in the Loess Plateau of China. PLoS ONE 7:1-10

McCool DK, Brown LC, Foster GR, Mutchler CK, Meyer LD (1987) Revised slope steepness factor for the Universal soil loss equation. Trans ASAE 30(5):1387-1396

Mohammad Ezz-Aldeen, Nadhir Al-Ansari, Sven Knutsson (2012) Application of SWAT model to estimate the runoff and sediment load from the right bank valleys of Mosul Dam reservoir. International Conference on Scour and Erosion (ICSE)-6: 27-31

Mou J (1996) Recent studies of the role o f soil conservation in reducing erosion and sediment yield in the Loess Plateau area of the Yellow River basin, International Association of Hydrological Sciences (IAHS Publications-Series of Proceedings and Reports) 236: 541-548

Nash JE, Sutcliffe J (1970) River flow forecasting through conceptual models part I—a discussion of principles. J Hydrol 10(3):282-290

Neitsch SL, Arnold JG, Kiniry JR, Williams JR (2009) Soil and water assessment tool. Theoretical documentation version. Texas Water Resources Institute Technical report No. 406, Texas A \& M University System, College Station, Texas 77843-2118, 2011
Ouyang W, Skidmore AK, Hao FH, Wang TJ (2010) Soil erosion dynamics response to landscape pattern. Sci Total Environ 408:1358-1366

Qiu LJ, Zheng FL, Yin RS (2012) SWAT-based runoff and sediment simulation in a small watershed, the loessial hilly-gullied region of China: capabilities and challenges. Int J Sedim Res 27:226-234

Sadeghi SHR, Mizuyama T (2007) Applicability of the modified universal soil loss equation for prediction of sediment yield in Khanmirza watershed. Iran. Hydrolog Sci J 52(5):1068-1075

Shi CX (2009) Effects of gravel content on soil erodibility and the methods of estimating soil erodibility factor K. Chin J Soil Sci 40(6):1398-1401 (in Chinese)

Shi H, Shao MG (2000) Soil and water loss from the Loess Plateau in China. J Arid Environ 45:9-20

Sun WY, Shao QQ, Liu JY, Zhai J (2014) Assessing the effects of land use and topography on soil erosion on the Loess Plateau in China. Catena 121:151-163

Wang WZ, Jiao JY (1996) Quantitative evaluation on factors influencing soil erosion in China. Bull Soil Water Conserv 16(5):1-19 (in Chinese)

Wang GQ, Chen JN, Li HB, Zeng ML (2003) Review on benefit assessment of water and soil conservation measures in Gushanchuan river basin. Northwest Water Resourc Water Eng 14(3):13-16 (in Chinese)

Wang GQ, Jiang H, Xu ZX, Wang LJ, Yue WF (2012) Evaluating the effect of land use changes on soil erosion and sediment yield using a grid-based distributed modeling approach. Hydrol Process 26:3579-3592

White MJ, Storm DE, Busteed PR, Smolen MD, Zhang HL, Fox GA (2010) A quantitative phosphorus loss assessment tool for agricultural fields. Environ Modell Softw 25:1121-1129

Williams JR (1995) Chapter 25: The EPIC model. In: Singh VP (ed) Computer models of watershed hydrology. Water Resources Publications, Highlands Ranch, pp 909-1000

Williams JR, Berndt HD (1977) Sediment yield prediction based on watershed hydrology. T ASAE 20(6):1100-1104

Wischmeier WH, Smith DD (1978) Predicting rainfall erosion losses: a guide to conservation planning, Washington, DC: USDA, 58p. Agriculture Handbook, 537

Zhang KL, Cai YM, Liu BY, Jiang ZS (2001a) Evaluation of soil erodibility on the Loess Plateau. Acta Ecologica Sin 21(10):1687-1695 (in Chinese)

Zhang KL, Cai YM, Liu BY, Peng WY (2001b) Fluctuation of soil erodibiliy due to rainfall intensity. Acta Geographica Sin 56(6):673-681 (in Chinese)

Zhang K, Li S, Peng W, Yu B (2004) Erodibility of agricultural soils on the Loess Plateau of China. Soil Tillage Res 76:157-165

Zhang Y, Degroote J, Wolter C, Sugumaran R (2009) Integration of modified universal soil loss equation (MUSLE) into a GIS framework to assess soil erosion risk. Land Degrad Dev 20:84-91

Zhang JX, Zhang B, Zhang H, Zhang DY, Dai SP, Ma ZH (2011) Landscape pattern change and soil erosion research-Take Malian River basin in Loess Plateau as an example. J Natural Resour 26(9):1513-1525 (In Chinese)

Zhou P, Wu C (1993) The research method of soil anti-scourability experiment in Loess Plateau. Acta Coserv Soli Et Aquae Sin 7(1):29-34 (in Chinese) 